\title{
Chemical profiling and antioxidant activity of Equisetum ramosissimum Desf. stem extract, a potential traditional medicinal plant for urinary tract infections
}

\author{
Jeyalatchagan Sureshkumar ${ }^{1 \dagger}$, Singamoorthy Amalraj ${ }^{2 \dagger}$, Ramar Murugan $^{3}$, Anantharaj Tamilselvan $^{4}$, \\ Jayaraj Krupa ${ }^{2}$, Venkatraman Sriramavaratharajan", Shailendra S. Gurav ${ }^{6}$ and Muniappan Ayyanar ${ }^{2 *}$ (1)
}

\begin{abstract}
Background: Equisetum ramosissimum Desf. (E. ramosissimum) is a widely used traditional medicinal plant to treat urinary tract infections (UTIs) by ethnic people throughout the world. The utility of the plant in treating urinary-related disorders was evaluated against selected pathogenic bacteria which has major role in causing UTIs. Hence, the present study executed to extract phytochemicals like total phenolics and flavonoids, chemical profiling by GC-MS analysis and to test their antioxidant activity from stem extracts of E. ramosissimum. The extraction process was directed by petroleum ether, chloroform, ethyl acetate, methanol, and aqueous solvents.

Results: The GC-MS analysis yielded 24 phytoconstituents with linoleic acid, palmitic acid, nonacosane, hexahydrofarnesyl acetone, and octacosane as major compounds. Methanolic extract yielded maximum amount of phenolics (TPC) and flavonoids (TFC) with 600.02 $\pm 0.22 \mathrm{mg} \mathrm{GAE} / \mathrm{g}$ and $631.38 \pm 0.69 \mathrm{mg}$ QE/g, respectively. Methanolic extract also exhibited notable free radical scavenging activity with an $I C_{50}$ of $123.89 \pm 0.73,150.10 \pm 1.02,146.01 \pm 0.54$, and $63.73 \pm 6.12 \mu \mathrm{g} / \mathrm{mL}$ for DPPH, FRAP, ABTS, and $\mathrm{O}_{2}{ }^{-}$assays, respectively. The minimum inhibitory concentration (MIC) required to inhibit the growth of tested pathogenic bacteria was observed in aqueous and methanolic extracts with the value being $31.25 \mu \mathrm{g} / \mathrm{mL}$ against $R$. equi and $V$. cholerae. As like, methanolic and petroleum ether extracts efficiently inhibited the growth of B. subtilis with the MIC of $31.25 \mu \mathrm{g} / \mathrm{mL}$.
\end{abstract}

Conclusion: It was concluded that the notable effect of methanolic and aqueous extracts against the uropathogenic bacteria reported in this study supported the traditional uses of this plant in treating UTIs. The results acquired from this investigation revealed that E. ramosissimum stem extract might be considered as an interesting candidate in the development of antibacterial agent against UTIs coupled with antioxidant properties.

Keywords: Antioxidants, Equisetaceae, GC-MS analysis, Urinary tract infections

\footnotetext{
*Correspondence: asmayyanar@yahoo.com

${ }^{\dagger}$ Jeyalatchagan Sureshkumar and Singamoorthy Amalraj contributed equally and treated as first authors.

${ }^{2}$ Department of Botany, A.V.V.M. Sri Pushpam College (Autonomous), Bharathidasan University, Poondi, Thanjavur 613 503, India

Full list of author information is available at the end of the article
}

\begin{abstract}
Background
Urinary tract infections (UTIs) are serious health problem with substantial clinical and financial burden affecting millions of people annually and especially women are more prone to be affected by the UTIs [1]. All UTIs are mostly caused by gram negative bacteria and Escherichia coli considered as most prevalent causative organism for UTIs with more than $90 \%$ of reported cases [2]. Various
\end{abstract}


species of Enterobacter, Enterococcus, Klebsiella, Proteus, Pseudomonas, and Staphylococcus also cause significant amount of UTIs in human. The UTIs caused by bacteria establish resistance by regular intake of antibiotics that also sometime less efficacious and cause side effects like neurotoxicity, nephrotoxicity, and hepatotoxicity [3]. Severe infections in the urinary tract may lead to various skin diseases including rashes and wounds [1]. Oral administration of renowned antibiotics such as trimethoprim, losporins, fluoroquinolone, and nitrofurantoin showed promising results as short time cure for UTIs [4].

Medicinal plants have been used as an alternative in managing infectious diseases with little or no adverse side effects [3]. To overcome the prevalent condition of UTIs, medicinal plants are widely used by the people since ancient times. The mechanism of herbal medicines used in treating UTIs is not well explained. But it was stated that secondary metabolites present in various parts of plants act as immunomodulators, boost/ regulate the body oxidant status by providing required amount of antioxidant compounds which in turn terminate the proliferation of microbes responsible for UTIs [5]. The major advantage in the use of medicinal plants and their bioactive constituents as potential herbal drugs is that the pathogenic bacteria have not developed resistance against them [6]. It may be due to the presence of rich amount of phytochemicals present in the herbal medicines.

While conducting a survey among the Malayali tribals in the Kolli hills of Eastern Ghats, it was noticed that they are frequently using the dried aerial parts of $E$. ramosissimum in the treatment of urinary-related diseases including stone formation in kidney, stomachache, skin diseases, bone fracture, joint pains, and rheumatism [6]. Likewise, the plant is broadly used by different ethnic people throughout the world in treating UTIs and related diseases like stone formation and kidney troubles $[7,8]$. Apart from its use in UTI infections, the plant has also used to treat inflammation, respiratory disorders, bone fracture, stomach problems, skin diseases (itching, scabies), gonorrhoea, rheumatism, female fertility, back pain, muscle pain, fever, sunstroke, and blood pressure [8].

The plant E. ramosissimum Desf. belongs to the family Equisetaceae and commonly referred as 'Horsetail'. The plant is widely distributed in Australia, USA, Africa, South Asia, India, Southeast China, Korea, and Japan. With the creeping subterranean rhizome, the plant is commonly distributed in sandy riverbanks of evergreen forests. In the study area, it is grown as a weed in cultivated lands of Kolli hills. The plant is reported to have monoterpenes, sesquiterpenes, sesquiterpene hydrocarbons, monoterpene hydrocarbons, $\alpha$-bisabolol oxide A, cumin aldehyde, carvacrol, $\alpha$-terpinyl-acetate, $\beta$-caryophyllene, hexadecanoic acid, thymol [9], kaempferol 3-O-sophoroside, kaempferol 3-O-sophoroside-7-O-glucoside [10], cholest-5-enol, 24-methylcholest-5-enol, 24-ethylchoesta-5,22-dienol, and 24-ethylcholest-5-enol [11].

Though the plant has much importance in traditional medicine with huge medicinal properties, there is a lacuna in chemical profiling of different extracts of the plant. With this backdrop information, the present investigation was envisioned to evaluate the GC-MS analysis, total phenolics content, total flavonoids content, and antioxidant activity of the E. ramosissimum stem using different solvents. The utility of the plant in treating urinary-related disorders was also evaluated against selected pathogenic bacteria which have a major role in causing UTIs.

\section{Methods \\ Chemicals}

The chemicals for the preparation of reagents (FolinCiocalteu reagent and Nash reagent) and buffers (phosphate buffer and acetate buffer) were of commercial grade (Sigma-Aldrich, Mumbai, India) and purchased from the local supplier, Techno Scientific, Thanjavur, 613 002 , India. Other chemicals and standard drugs used in the study were also purchased from the same supplier with the commercial brand of Merck Life Science Pvt. Ltd. Mumbai, India.

\section{Collection and preparation of plant extracts}

The stem of E. ramosissimum used in this study was collected during August 2019 from Kolli hills of Namakkal district, India, at an altitude of $901-1100 \mathrm{~m}$. The provisional identification of this specimen was performed using the standard flora 'Pteridophytic flora of the Western Ghats in South India' [12] and further authenticated by the taxonomists at the 'Malabar Botanical Garden and Institute for Plant Sciences' Kozhikode, Kerala, by submitting a preserved herbarium specimen. The wellprepared voucher specimen (SPCH1070) was submitted in the herbarium of host institution for future references.

The extraction was done using petroleum ether, chloroform, ethyl acetate, methanol, and aqueous solvents which have a wide range of polarity. Briefly, the powdered stem material was macerated to aforesaid solvents in the ratio of $1: 5$ and kept under shaker at $125 \mathrm{rpm}$ for $8 \mathrm{~h}$ at about $40{ }^{\circ} \mathrm{C}$. Filtration was done through muslin cloth and Whatman No. 1 filter paper. The excess solvent was removed by vacuum distillation to yield crude extract. The crude extracts were evaporated by reduced pressure at $40{ }^{\circ} \mathrm{C}$ in an evaporator except for aqueous extract. 
Then, concentrated extracts were stored in tightly sealed glass containers at $-20{ }^{\circ} \mathrm{C}$ for further studies.

\section{Phytochemical analysis Qualitative analysis of phytochemicals}

The preliminary phytochemical screening of E. ramosissimum stem extract was done to find out the presence of different phytochemicals such as steroids (Salkowski test), triterpenoids (Liebermann-Burchard reaction), alkaloids (Hager's test), phenolic compounds (Lead acetate test), flavonoids (Alkaline reagent test), saponins (Frothing test), and tannins (Potassium hydroxide test) using standard methods [13].

\section{GC-MS analysis of stem extract}

Gas chromatography-mass spectrometry analysis was carried out in Shimadzu (QP-2020) interfaced to a mass spectrometer for the petroleum ether, ethyl acetate, and methanol extracts of E. ramosissimum stem. The TD20 was used to obtain the chromatogram using the AB-Innowax column. The initial temperature was programmed with $50{ }^{\circ} \mathrm{C}$ and extended up to $280{ }^{\circ} \mathrm{C}$ at $40{ }^{\circ} \mathrm{C} \mathrm{min}^{-1}$. Helium was used as carrier gas and the ion source temperature was maintained as $200{ }^{\circ} \mathrm{C}$. Identification of detected compounds in the stem extracts was measured by computing the usual peak area to total area and electronic libraries [14].

\section{Determination of total phenolics (TPC) and flavonoids (TFC) content}

The quantitative estimation of TPC in various solvent extracts of E. ramosissimum stem was done by the FolinCiocalteu method [15]. About $0.5 \mathrm{~mL}$ of $1 \mathrm{~N}$ Folin-Ciocalteu reagent was added with $2.5 \mathrm{~mL}$ of $20 \%$ sodium carbonate solution to each tube of stem extract at different concentrations. The absorbance was recorded at $725 \mathrm{~nm}$ against blank which possess water alone. Gallic acid was used as standard and the results were expressed in terms of milligrams gallic acid equivalents per gram of extracts. The TFC was estimated by $\mathrm{AlCl}_{3}$ method [15]. Briefly, $300 \mu \mathrm{L}$ of various concentration of stem extract was added with $2 \mathrm{~mL}$ of distilled water followed by $150 \mu \mathrm{L}$ of $\mathrm{NaNO}_{2}$. Then, $150 \mu \mathrm{L}$ of $\mathrm{AlCl}_{3}$ was added and incubated for $6 \mathrm{~min}$. To this, $2 \mathrm{~mL}$ of $4 \% \mathrm{NaOH}$ was added, vortexed, and kept at $37^{\circ} \mathrm{C}$. The absorbance was read at $510 \mathrm{~nm}$ against blank. Quercetin was used as standard and the results were expressed as milligrams quercetin equivalents per gram of extract.

\section{In vitro antioxidant activity}

The antioxidant potential of different solvent extracts of E. ramosissimum stem was determined by five in vitro assays. Absorbance was measured on 96 well microplate reader (Robonik India Pvt. Ltd., Thane, India). The DPPH free radical scavenging, FRAP, ABTS, $\mathrm{O}_{2}{ }^{-}$, and $\mathrm{OH}^{-}$free radical scavenging abilities of $E$. ramosissimum stem extracts were studied as defined in our earlier study [16]. Reference antioxidant used in all the assays was ascorbic acid. For each concentration, the percentage inhibition of standard and test samples was calculated and the graph was drawn between percentage inhibition and concentration. From the obtained graphs, the $\mathrm{IC}_{50}$ was computed as the concentration at which $50 \%$ of inhibition observed against the concentration of $E$. ramosissimum stem extract.

\section{Antibacterial activity \\ Bacterial strains used}

The stem extracts of E. ramosissimum were studied against four gram positive strains like Staphylococcus epidermidis (MTCC435), Bacillus subtilis (MTCC441), Rhodococcus equi (MTTC2558), and Methicillin resistant Staphylococcus aureus (B23), and gram negative strains such as Escherichia coli (MTCC40), Vibrio cholerae (MTTC3904), Salmonella typhi (MTCC3224), Pseudomonas aeruginosa (MTCC1748), Klebsiella oxytoca (B847), and Citrobacter freundii (B15) which are major causative agents of UTIs.

\section{Broth microdilution method}

The minimum inhibitory concentration required to inhibit the growth of pathogenic bacteria with E. ramosissimum stem extract was performed by microdilution method using 96 well plates [17]. For the experiment, $50 \mu \mathrm{L}$ of stem extract at 500 to $0.488 \mu \mathrm{g} / \mathrm{mL}$ concentrations was obtained using serial dilution method. Fifty $\mu \mathrm{L}$ of Mueller-Hinton broth was poured in each well. Then, $50 \mu \mathrm{L}$ of bacterial inoculum was added to each well and incubated for $24 \mathrm{~h}$ at $37^{\circ} \mathrm{C}$. Then, $20 \mu \mathrm{L}$ of INT (p-iodonitro-tetrazolium chloride) was added and incubated for $30 \mathrm{~min}$ at $37{ }^{\circ} \mathrm{C}$. Ampicillin and Deflox were $(30-0.029 \mu \mathrm{g} / \mathrm{mL})$ used as positive controls. The MIC of stem extract was observed by change in colour after the addition of INT dye. The bacterial growth was predicted by red-pink colour in wells and no colour change indicated the inhibition of bacterial growth with stem extract.

\section{Statistical analysis}

All the experimental parts were done in triplicate and the results were calculated as mean \pm standard deviation. All the statistical analysis was considered highly significant with more than $95 \%$ confidence interval. The graphical representations were done with GraphPad Prism version 8.0.2 (GraphPad Software, Inc). 


\section{Results}

\section{Phytochemical profiling}

The extract yield of E. ramosissimum stem was recorded as $3.91,3.55,5.86,8.96$, and $4.70 \%$ in petroleum ether, chloroform, ethyl acetate, methanol, and aqueous solvents, respectively. Qualitative phytochemical screening of E. ramosissimum stem showed the presence of tested secondary metabolites in most of the solvents used in the study (Table 1). Phenolic compounds were noticed in all the five extracts. Flavonoids, steroids, and tannins were found in petroleum ether, chloroform, methanol, and aqueous extracts. While triterpenoids were present in chloroform and methanolic extracts, alkaloids were found in petroleum ether, ethyl acetate, and methanolic extracts. Saponins were detected in ethyl acetate, methanol, and aqueous extracts.

The GC-MS analysis of E. ramosissimum stem extract yielded 24 compounds. The analysis enabled the identification of 10,15 , and 13 compounds amounting to 90.8 , 96.1, and $98.4 \%$ for petroleum ether, ethyl acetate, and methanolic extracts, respectively (Table 2). Linoleic acid, palmitic acid, and octacosane are recorded as dominant compounds in the petroleum ether extract of E. ramosissimum stem with 41.4, 19.4, and 6.9\%, respectively (Fig. 1a). Campesterol is one of the sterol groups of compound present in petroleum ether extract. In ethyl acetate extract, palmitic acid (34.4\%), nonacosane (11.5\%), and hexahydrofarnesyl acetone (9.4\%) were identified as major constituents (Fig. 1b). As like, methanolic extract also contributes palmitic acid (44.3\%) and hexahydrofarnesyl acetone (9.8\%) as major constituents followed by nonacosane (7.8\%) and $n$-tetracosane (6.9\%) (Fig. 1c).

The measured levels of TPC and TFC are presented in Fig. 2. The gallic acid equivalent was computed from linear regression of standard calibration curve $\left(y=0.0113+0.204 ; R^{2}=0.9931\right)$ for TPC. The TPC was ranged from $58.67 \pm 2.57$ to $600.02 \pm 0.22 \mathrm{mg} \mathrm{GAE} / \mathrm{g}$. The maximum amount of TPC was recorded in methanolic extract with $600.02 \pm 0.22 \mathrm{mg}$ GAE/g followed by petroleum ether and aqueous extracts with $393.48 \pm 14.36$ and $303.77 \pm 3.84 \mathrm{mg} \mathrm{GAE} / \mathrm{g}$, respectively. The TFC of $E$. ramosissimum extract varied in the ranges of $47.93 \pm 1.55$ to $631.38 \pm 0.69 \mathrm{mg} \mathrm{QE} / \mathrm{g}$. For quantification of TFC, quercetin equivalent was calculated from linear regression of standard calibration curve $(y=0.0117+0.1018$; $\left.R^{2}=0.9907\right)$. The TFC was also higher in methanolic extract $(631.38 \pm 0.69 \mathrm{mg} \mathrm{QE} / \mathrm{g})$ followed by aqueous and petroleum ether extracts with $493.77 \pm 0.96$ and $405.14 \pm 9.43 \mathrm{mg}$ QE/g, respectively.

\section{Antioxidant activity}

In vitro antioxidant activity of $E$. ramosissimum stem extract was studied by DPPH, ABTS, $\mathrm{O}_{2}{ }^{-}, \mathrm{OH}^{-}$, and FRAP methods (Fig. 3). The lower the $\mathrm{IC}_{50}$ values, higher the antioxidant activity of plant extract. The E. ramosissimum stem had comparable $\mathrm{IC}_{50}$ values for $\mathrm{DPPH}$ free radical scavenging capacity in tested concentrations $(2.5$, $5,10,20,40,80$, and $160 \mu \mathrm{g} / \mathrm{mL})$. Methanolic extract at a concentration of $160 \mu \mathrm{g} / \mathrm{mL}$ showed highest free radical scavenging ability with an $\mathrm{IC}_{50}$ of $123.89 \pm 0.73 \mu \mathrm{g} /$ $\mathrm{mL}$ followed by ethyl acetate and aqueous extracts ( $146.46 \pm 0.54$ and $154.93 \pm 0.54 \mu \mathrm{g} / \mathrm{mL}$, respectively). It was observed that significant difference was found in petroleum ether $(p \leq 0.0001)$ and chloroform $(p=0.005)$ extracts. However, methanol and ethyl acetate extracts were showed no significance difference when compared to the standard. Similar to DPPH assay, methanolic extract of E. ramosissimum stem at $160 \mu \mathrm{g} / \mathrm{mL}$ concentration showed higher reducing power in FRAP method with an $\mathrm{IC}_{50}$ of $150.10 \pm 1.02 \mu \mathrm{g} / \mathrm{mL}$ and least activity was observed in petroleum ether extract $\left(\mathrm{IC}_{50}\right.$ of $248.12 \pm 2.50 \mu \mathrm{g} / \mathrm{mL}$ ). However, petroleum ether, chloroform, and ethyl acetate extracts are statistically different from the reference compound.

For the ABTS assay, highest free radical scavenging activity was recorded in methanolic and aqueous extracts at $160 \mu \mathrm{g} / \mathrm{mL}$ concentration with an $\mathrm{IC}_{50}$ of $146.01 \pm 0.54$ and $162.42 \pm 0.49 \mu \mathrm{g} / \mathrm{mL}$, respectively. These extracts were observed with no significant difference to the standard. On the other hand, petroleum ether and chloroform

Table 1 Qualitative phytochemical screening of E. ramosissimum stem extracts

\begin{tabular}{|c|c|c|c|c|c|}
\hline Phytochemicals tested & Petroleum ether & Chloroform & Ethyl acetate & Methanol & Aqueous \\
\hline Steroids & + & + & - & ++ & ++ \\
\hline Triterpenoids & - & ++ & - & + & - \\
\hline Alkaloids & + & - & + & +++ & - \\
\hline Phenolic compounds & ++ & + & + & +++ & ++ \\
\hline Flavonoids & + & + & - & +++ & ++ \\
\hline Saponins & - & - & + & + & + \\
\hline Tannins & + & + & - & ++ & +++ \\
\hline
\end{tabular}

The symbols,,++++++ , and - refer to appreciable, moderate, trace amounts, and absence of secondary metabolites, respectively, in the tested solvent extracts 
Table 2 GC-MS analysis of petroleum ether, ethyl acetate, and methanolic extracts of Equisetum ramosissimum stem

\begin{tabular}{|c|c|c|c|c|c|}
\hline \multirow[t]{2}{*}{ S. no } & \multirow[t]{2}{*}{ Retention time } & \multirow[t]{2}{*}{ Compounds } & \multicolumn{3}{|c|}{ Area \% } \\
\hline & & & $\overline{\mathrm{PE}}$ & EA & ME \\
\hline 1 & 17.279 & Methyl palmitate & 4.9 & - & - \\
\hline 2 & 17.330 & n-Tridecane & - & 3.5 & - \\
\hline 3 & 17.669 & 3,7,11,15-Tetramethyl-2-hexadecen-1-ol & - & - & 3.8 \\
\hline 4 & 17.725 & Neophytadiene & - & 2.7 & - \\
\hline 5 & 17.875 & Hexahydrofarnesyl acetone & - & 9.4 & 9.8 \\
\hline 6 & 17.904 & Ethyl palmitate & 4.7 & - & - \\
\hline 7 & 18.855 & Methyl linoleate & 3.8 & - & - \\
\hline 8 & 18.930 & Methyl 9,12,15-octadecatrienoate & 4.3 & - & - \\
\hline 9 & 19.315 & Palmitic acid & 19.4 & 34.4 & 44.3 \\
\hline 10 & 19.765 & Linoleic acid & 41.4 & - & - \\
\hline 11 & 21.196 & $n$-Eicosane & - & 2.9 & - \\
\hline 12 & 21.266 & Cyclopentanecarboxylic acid, 4-methylpentyl ester & - & - & 2.1 \\
\hline 13 & 21.381 & Sulphurous acid, cyclohexylmethyl hexyl ester & - & 3.1 & - \\
\hline 14 & 24.172 & 1-Docosene & - & 1.8 & 1.6 \\
\hline 15 & 24.702 & $n$-Docosane & - & 2.2 & 3.1 \\
\hline 16 & 25.503 & $n$-Tricosane & - & 2.5 & 3.7 \\
\hline 17 & 26.053 & n-Tetracosane & - & 4.2 & 6.9 \\
\hline 18 & 26.228 & Hexacosane & 2.6 & 3.5 & 3.5 \\
\hline 19 & 27.638 & Heptacosane & - & 7.8 & 8.1 \\
\hline 20 & 27.733 & Campesterol & 2.3 & - & - \\
\hline 21 & 27.808 & Squalene & - & - & 1.5 \\
\hline 22 & 27.933 & Octacosane & 6.9 & 3.7 & 2.2 \\
\hline 23 & 30.100 & Nonacosane & - & 11.5 & 7.8 \\
\hline \multirow[t]{2}{*}{24} & 31.070 & Solanesol & - & 2.9 & - \\
\hline & & Total & 90.8 & 96.1 & 98.4 \\
\hline
\end{tabular}

$P E$ petroleum ether, $E A$ ethyl acetate, $M E$ methanol

extracts were positively significant $(p \leq 0.0001)$ among the tested extracts. Likewise, aqueous and methanolic extracts at $160 \mu \mathrm{g} / \mathrm{mL}$ showed highest superoxide scavenging activity with an $\mathrm{IC}_{50}$ of $63.73 \pm 6.12$ and $82.18 \pm 2.39 \mu \mathrm{g} / \mathrm{mL}$, respectively. The higher hydroxyl free radical scavenging activity was recorded at the concentration of $160 \mu \mathrm{g} / \mathrm{mL}$ in methanolic, aqueous, and chloroform extracts with an $\mathrm{IC}_{50}$ of $122.91 \pm 3.32$, $144.87 \pm 1.30$, and $169.31 \pm 1.76 \mu \mathrm{g} / \mathrm{mL}$, respectively. In which, highest significance in difference was observed in petroleum ether $(p \leq 0.0001)$ and ethyl acetate extracts $(p=0.005)$.

\section{Antibacterial activity}

The results of the MIC value of the E. ramosissimum stem extracts are represented in Table 3 , and inhibition images are provided as Additional files 1 and 2. Aqueous and methanolic extracts showed excellent MIC which requires just $31.25 \mu \mathrm{g} / \mathrm{mL}$ of plant extract to inhibit the growth of $R$. equi and V. cholerae. Methanolic and petroleum ether extracts efficiently inhibited the growth of
B. subtilis at $31.25 \mu \mathrm{g} / \mathrm{mL}$ concentration. The growth of B. subtilitis is commendably controlled by all the tested solvent extracts at lower concentration of plant extracts $(31.25-125 \mu \mathrm{g} / \mathrm{mL})$. However, $C$. freundii is susceptible for most of the tested solvent extracts at even higher concentrations except aqueous $(62.5 \mu \mathrm{g} / \mathrm{mL})$ and ethyl acetate $(125 \mu \mathrm{g} / \mathrm{mL})$ extracts.

\section{Discussion}

The presence or absence of different phytochemicals in plant extract plays a major role in antioxidant and antibacterial activities of a specific plant part [18]. In the present study, qualitative phytochemical screening of E. ramosissimum revealed the presence of significant amount of secondary metabolites like phenolics, flavonoids, steroids, and tannins (Table 1). Previous studies also confirmed the presence of various phytochemicals in different parts of E. ramosissimum as reported in the present work [10, 11]. To support our study, Chiu et al. [10] also identified sterol compounds from aerial parts of $E$. ramosissimum with chloroform-methanolic extract. 

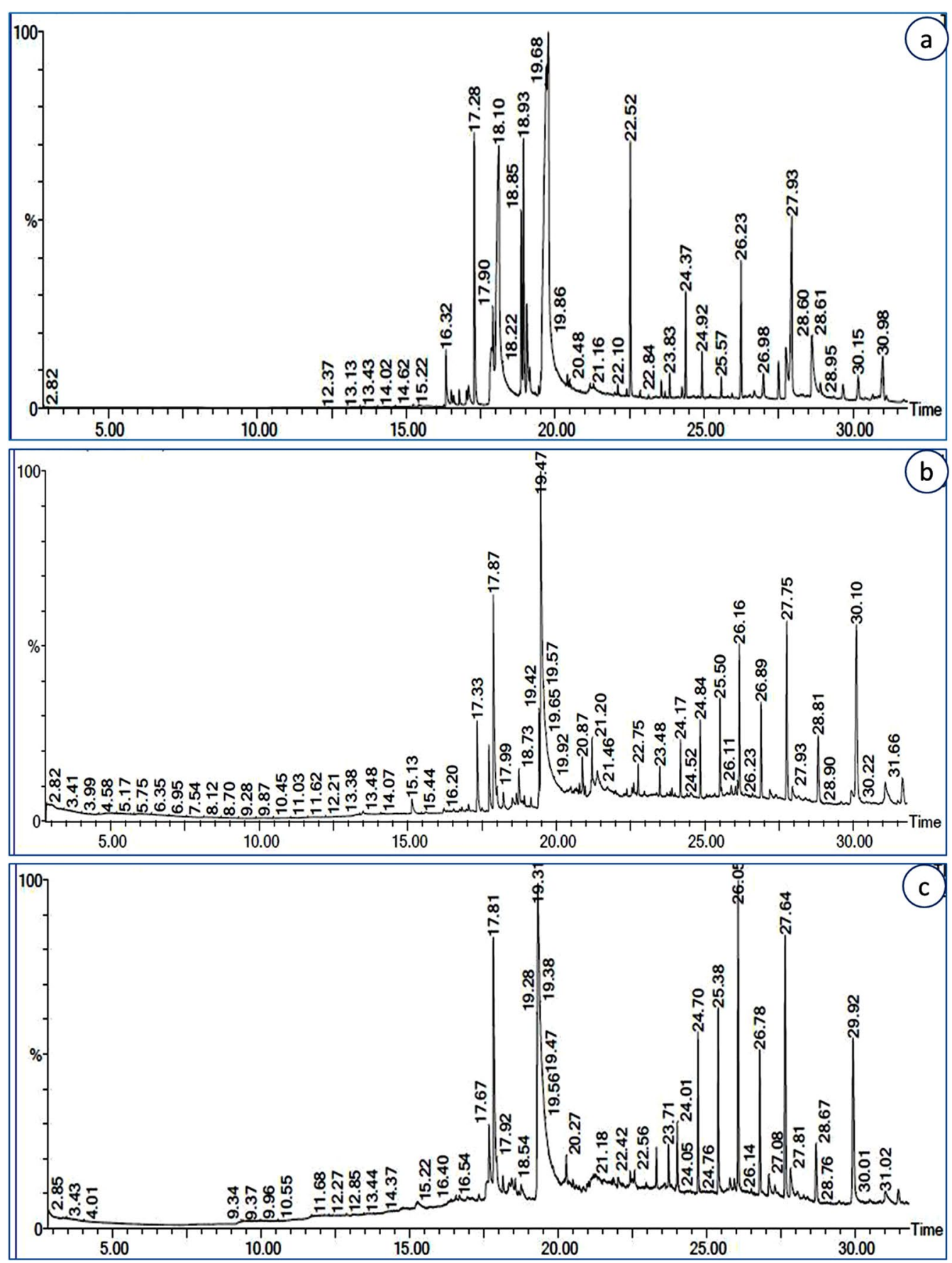

Fig. 1 GC-MS analysis of the petroleum ether (a), ethyl acetate (b), and methanol (c) extracts of E. ramosissimum Desf. stem

The phytochemical analysis of E. ramosissimum stem extract using GC-MS showed the presence of 24 compounds with palmitic acid (44.3, 34.4, and $19.4 \%$ in methanolic, ethyl acetate, and petroleum ether extracts, respectively) and linoleic acid (41.4\% in petroleum ether extract) as major constituents (Table 2). Palmitic acid is a saturated fatty acid (16-C long chain molecule), an essential component for human body and could be supplemented in diet or made endogenously from the other fatty acids, amino acids, and carbohydrates [19]. It has a major pathological role in metabolic syndromes, cancer, inflammation, cardiovascular, and neurodegenerative diseases and major proportion 


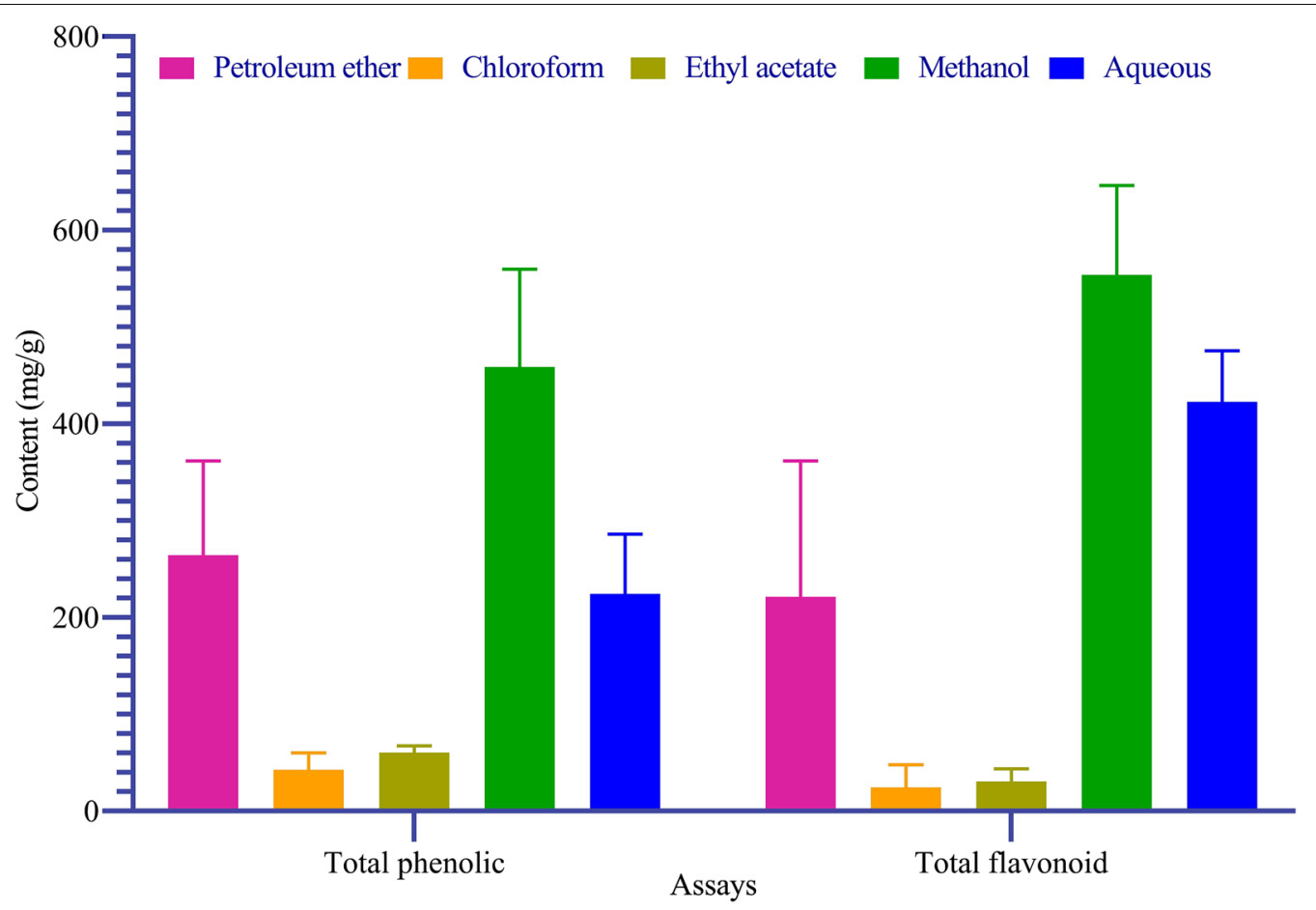

Fig. 2 Total phenolics and flavonoids content in E. ramosissimum stem extracts

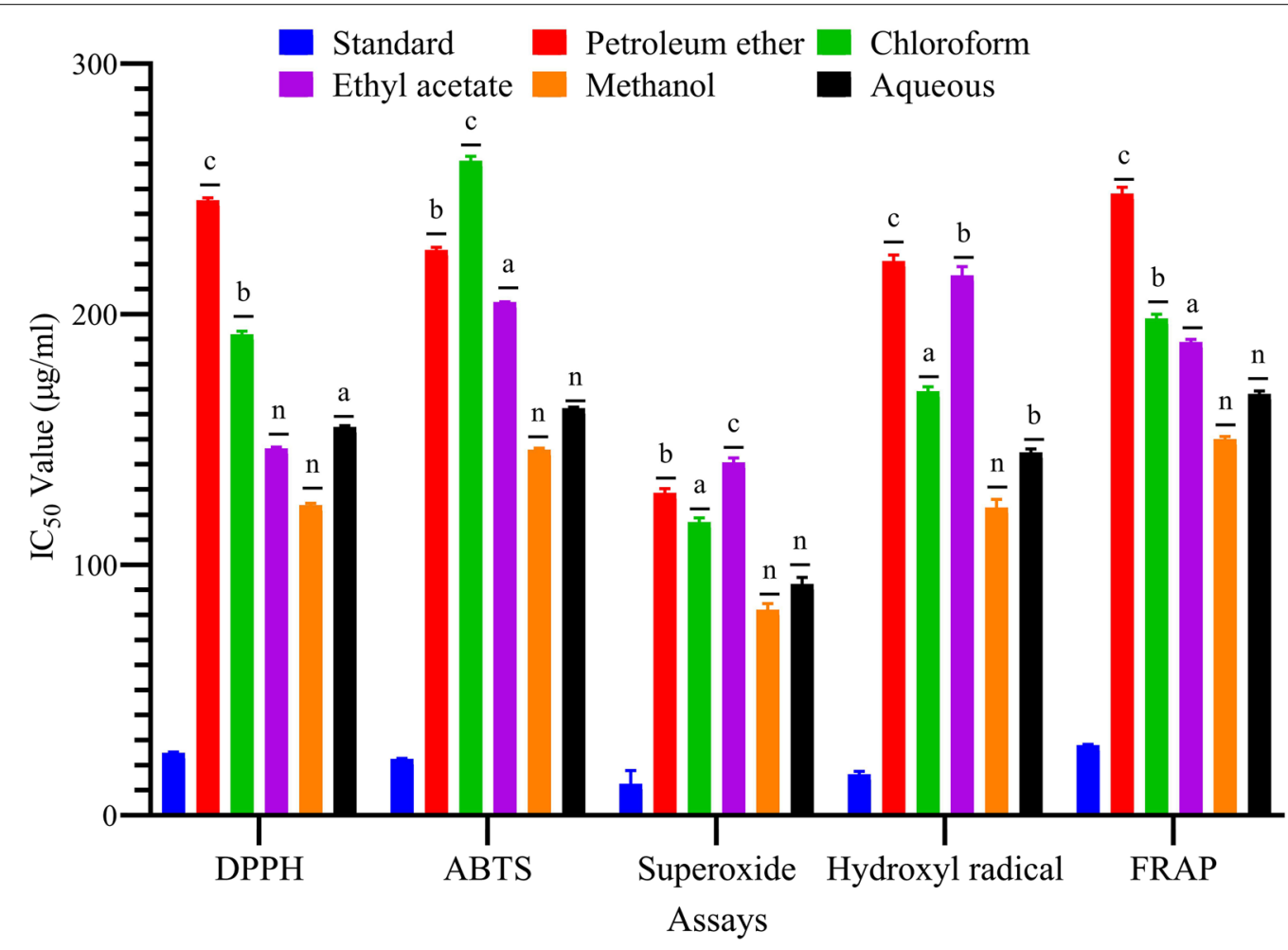

Fig. 3 In vitro antioxidant activity of E. ramosissimum Desf. stem extracts by DPPH, ABTS, superoxide, hydroxyl radical scavenging, and FRAP assays. Different letters in the graph indicate significant differences $(\mathbf{a} p \leq 0.05 ; \mathbf{b} p \leq 0.01 ; \mathbf{c} p \leq 0.001 ; n$, no significance) in the tested extracts with the reference standard, ascorbic acid 
Table 3 Minimum inhibitory concentration of E. ramosissimum leaf extracts against the selected pathogenic bacteria

\begin{tabular}{lllllllllll}
\hline Extracts & \multicolumn{1}{l}{ Minimum inhibitory concentration $(\boldsymbol{\mu g} / \mathbf{m L})$} \\
\cline { 2 - 12 } & E. coli & MRSA & S. epidermis & B. subtilis & R. equi & V. cholerae & S. typhi & K. oxytoca & P. aeruginosa & C. freundii \\
\hline Petroleum ether & $>500$ & $>500$ & $>500$ & 31.25 & $>500$ & $>500$ & $>500$ & $>500$ & $>500$ & $>500$ \\
Chloroform & 500 & $>500$ & $>500$ & 125 & $>500$ & $>500$ & 500 & 125 & 250 & $>500$ \\
Ethyl acetate & 250 & $>500$ & $>500$ & 125 & 250 & 15.625 & 250 & 500 & 125 & 125 \\
Methanol & 250 & 125 & 62.5 & 31.25 & 125 & 250 & 62.5 & 62.5 & 62.5 & 500 \\
Aqueous & 250 & 125 & 125 & 62.5 & 31.25 & 31.25 & 125 & 125 & 62.5 & 62.5 \\
Ampicillin (Std.) & 0.937 & 3.75 & 7.5 & 1.875 & 0.937 & 7.5 & 15 & 15 & 1.875 & 0.234 \\
Deflox (Std.) & $<0.029$ & $<0.029$ & $<0.029$ & $<0.029$ & $<0.029$ & $<0.029$ & $<0.029$ & $<0.029$ & $<0.029$ & $<0.029$ \\
\hline
\end{tabular}

of saturated fatty acids found in human body cells and serum are comprising of this palmitic acid [20].

As reported in our study, Alebous et al. [11] also revealed the presence of linoleic acid (4.6\%) in essential oil extracted from aerial parts of E. ramosissimum. Linoleic acid is one of the important polyunsaturated fatty acids which is necessary energy per day (at least 1-2\%) for normal human growth and development process and considered as a precursor in the synthesis of arachidonic acid and eicosanoids [21]. The compound is most commonly found in the seeds, nuts, oils, and cereals of various plants and major vegetable oils like corn, olive, cotton seed, palm, sunflower, and coconut comprising about $1 \%$ of linoleic acid [22]. Linoleic acid is also involved in various health promoting properties like reducing the catabolic effects of immune stimulation, facilitates growth regulation and promotion, reduces body fat, anticarcinogenic and antiatherogenic activities [23].

Among the 24 compounds recorded in our study, only palmitic acid, hexacosane, and octacosane are noticed in all the tested extracts (Table 2 and Fig. 1). The compounds like, $n$-tridecane, methyl palmitate, neophytadiene, 3,7,11,15-tetramethyl-2-hexadecen-1-ol, ethyl palmitate, methyl linoleate, linoleic acid, $n$-eicosane, methyl 9,12,15-octadecatrienoate, sulphurous acid, cyclohexylmethyl hexyl ester, cyclopentane carboxylic acid, bis(2-ethylhexyl) phthalate, 4-methylpentyl ester, campesterol, squalene, and solanesol were recorded as least represented phytochemicals in any one of the solvent extract.

Flavonoids are one of the major types of polyphenols and most of them have been reported to have antioxidant, anti-inflammatory, and antidiabetic activities [24]. The amount of TPC observed in the present study was noticeably higher than the earlier reports. Previously, methanolic extract of the stem of Equisetum telmateia (E. telmateia) was recorded with $262.7 \pm 1.0 \mathrm{mg} \mathrm{RU} / \mathrm{g}$ pf TPC [25]. Stajner et al. [26] reported $1.75 \pm 0.09 \mathrm{mg} / \mathrm{g}$ of TFC in aerial parts of E. ramosissimum phosphate buffer extract. The results of this study revealed that the extracts of high polar solvents like methanol and aqueous showed highest amount of TPC and TFC in E. ramosissimum stem which showed highest extraction efficiency (Fig. 2). The polarity of solvent has a significant role in quantity of TPC and the efficiency of extraction for TPC and TFC is reduced with the decrease in polarity of solvents. It was well known that hydrophilic and hydrophobic features of phytochemicals recorded a high influence on their solubility, and hence, polarity of solvents used has a potential role in extracting efficiency of these phytocompounds [27].

Antioxidants can diminish the adverse effects of free radicals, viz., reactive oxygen species (ROS) and reactive nitrogen species (RNS) that are generated during cellular metabolism. The ROS exert supportive effects on cellular redox signalling and immune functioning even at low concentrations. At higher concentrations, ROS and RNS deregulate several cellular functions and often lead to diverse pathological illnesses [28]. The use of plantbased natural antioxidants like flavonoids, phenolics, and tocopherols are biologically act at molecular level and reported to inhibit/reduce the formation of free radicals [29]. Antioxidant capacity of plant extracts could be due to the existence of polyphenolic compounds which have the ability to donate hydrogen atoms to their hydroxyl groups [17].

The DPPH was used as a source of free radicals, since it simulates ROS and RNS by in vitro that affect biological systems and involved in inhibiting the oxidative stressinduced cellular damage and lipid peroxidation [30]. To support our study, significant free radical scavenging effect with the DPPH method was reported by Paulsamy et al. [31] in methanolic extracts of E. ramosissimum whole plant with an $\mathrm{IC}_{50}$ of $78.58 \mu \mathrm{g} / \mathrm{mL}$. According to Li et al. [32], ethyl acetate extract of E. ramosissimum at $200 \mu \mathrm{g} / \mathrm{mL}$ showed comparable DPPH activity with an $\mathrm{IC}_{50}$ of $43.41 \pm 7.68 \mu \mathrm{g} / \mathrm{mL}$. Previously, Stajner et al. [26] reported comparable antioxidant effect of aerial parts of 
E. ramosissimum, Equisetum arvense (E. arvense), and E. telmateia with phosphate buffer extracts using FRAP methods with an effective $\mathrm{IC}_{50}$ of $5.44 \pm 0.72,2.85 \pm 0.45$, and $44.1 \pm 2.11 \mu \mathrm{g} / \mathrm{mL}$, respectively.

Methanolic extract of whole plant parts of E. ramosissimum showed ABTS scavenging activity of $1946.36 \pm 2.12 \mu \mathrm{m}$ of TE/g DW [31] as like our study. Also, ethanolic extract of $E$. arvense exhibited higher scavenging activity in ABTS assay with an $\mathrm{IC}_{50}$ of $98.13 \pm 3.84$ [33]. Our results of $\mathrm{O}_{2}{ }^{-}$radical scavenging activities are in accordance with studies of Nagai et al. [34] who reported significant $\mathrm{O}_{2}^{-}$radical scavenging activities of aqueous and ethanolic extracts of E. arvense aerial parts with 7.33 and $54.2 \%$ of inhibition, respectively. They also reported 12.8 and $80.6 \%$ of inhibition by the stem of $E$. arvense with aqueous and ethanol extracts. Likewise, Canadanovic-Brunet et al. [35] reported the $\mathrm{OH}^{-}$radical scavenging effect of the ethyl acetate and aqueous extracts of $E$. arvense aerial parts with the $\mathrm{EC}_{50}$ of $2.29 \pm 0.11$ and $3.29 \pm 0.16 \mathrm{mg} \mathrm{mL}^{-1}$, respectively. The values for antioxidant activity of methanolic and aqueous extracts of E. ramosissimum stem exhibited no significant changes in ABTS, hydroxyl radical, superoxide, and FRAP assays (Fig. 3).

The stem extracts of E. ramosissimum were effective against the growth of pathogenic bacteria (done by microdilution method) like S. epidermidis, B. subtilis, $R$. equi, MRSA, E. coli, V. cholerae, S. typhi, P. aeruginosa, $K$. oxytoca, and C. freundii which are recognized as wellknown causative agents of UTIs (Table 3 and supplementary file). Sarkar et al. [36] reported a high degree of antibacterial activity in ethyl acetate extract of E. ramosissimum whole plant against $E$. coli and $S$. aureus with the zone of inhibition of 7-8 $\mathrm{mm}$. Ethyl acetate extracts of the aerial parts of Equisetum hyemale showed good range of antibacterial activity $(13.1-52.4 \mathrm{mg} / \mathrm{mL})$ against the bacterial strains $S$. aureus, E. coli, and P. aeruginosa [37].

\section{Conclusions}

In the present study, we perceived for the first time that all the tested extracts derived from the E. ramosissimum stem possessed antioxidant and antibacterial properties. The GC-MS analysis of stem extract yielded 24 compounds with palmitic acid, linoleic acid, nonacosane, hexahydrofarnesyl acetone, and octacosane as prominent compounds. Our data suggest that the potency of tested biological activities is higher in polar solvents with considerable result in methanolic extract. The extracts recorded with significant amount of total phenolics and flavonoids exhibited significant antioxidant properties and antibacterial activities against the pathogenic bacteria. The notable effect of methanolic and aqueous extracts against the uropathogenic bacteria supported the traditional uses of this plant in treating UTIs. The isolation of pure bioactive compounds may have the potential usage to improve and manage novel drugs in treating UTIs by investigating in vivo methods. Further investigations still need to be conducted on toxicity of stem extracts to effectively maximize human health benefits. This study draws attention to methanolic extracts of the stem of E. ramosissimum as a potent source of active principles that can be further utilized as a prominent bioresources in drug discovery efforts.

\section{Abbreviations}

ABTS: 2,2'-Azino-bis (3-ethylbenzo-thiozoline-6-sulfonic acid); $\mathrm{AlCl}_{3}$ : Aluminium chloride; DMSO: Dimethyl sulphoxide; DPPH: 2,2-Diphenyl-1-picrylhdrazyl; E. arvense: Equisetum arvense; E. ramosissimum: Equisetum ramosissimum; E. telmateia: Equisetum telmateia; FRAP: Ferric reducing antioxidant power; GC-MS: Gas chromatography-mass spectrometry; MHA: Mueller-Hinton Ager; MIC: Minimum inhibitory concentration; $\mathrm{O}^{2-}$ : Superoxide radical scavenging; $\mathrm{OH}^{-}$: Hydroxyl free radical scavenging; TFC: Total flavonoid content; TPC: Total phenolic content; UTI: Urinary tract infection.

\section{Supplementary Information}

The online version contains supplementary material available at https://doi. org/10.1186/s43094-021-00339-8.

Additional file 1. Results of the minimum inhibitory concentrations of $E$. ramosissimum stem extracts.

Additional file 2. Raw data for the results of quantitative phytochemical investigation, antioxidant and antibacterial activities of E. ramosissimum stem extracts.

\section{Acknowledgements}

The authors gratefully acknowledge the Principal and Management of A.V.V.M. Sri Pushpam College (Autonomous), Poondi, Thanjavur, for their encouragement and support.

\section{Authors' contributions}

JS, SA, JK, and AT evaluated the experimental data of antioxidant, phytochemical screening, and antibacterial activity. They also carried out the bioassay parts and drafted the manuscript. RM contributed to the characterization of GC-MS analysis. SSG and RM were accompanied in supervision of experimental part along with MA. VS contributed and helped in statistical analysis of the obtained results. MA revised the manuscript and supervised overall experimental and writing process. All authors read and approved the final version of the manuscript.

\section{Funding}

The authors are grateful to Science and Engineering Research Board, (Grant No. EMR/2016/007164), Department of Science and Technology, Govt. of India, New Delhi, for financial support.

\section{Availability of data and materials}

The data obtained in the results of the study will be produced on request from the readers of manuscript as well as publishers, when required.

\section{Declarations}

Ethics approval and consent to participate Not applicable. 


\section{Consent for publication \\ Not applicable.}

\section{Competing interests}

All authors declare that there are no conflicts of interest.

\section{Author details}

${ }^{1}$ Department of Botany, Annai Vailankanni Arts and Science College (Affiliated to Bharathidasan University), Thanjavur, Tamil Nadu 613 007, India. ${ }^{2}$ Department of Botany, A.V.V.M. Sri Pushpam College (Autonomous), Bharathidasan University, Poondi, Thanjavur 613 503, India. ${ }^{3}$ Centre for Research and Postgraduate Studies in Botany, Ayya Nadar Janaki Ammal College (Autonomous), Sivakasi 626 124, India. ${ }^{4}$ Department of Botany, Government Arts and Science College, Tamil Nadu, Sivakasi 626 124, India. ${ }^{5}$ Virchow Biotech Private Limited, Survey No.172 part, Gagillapur, Hyderabad, India. ${ }^{6}$ Department of Pharmacognosy, Goa College of Pharmacy, Goa University, Panaji, Goa 403 001, India.

Received: 7 May 2021 Accepted: 13 September 2021

Published online: 23 September 2021

\section{References}

1. Patel HB, Soni ST, Bhagyalaxmi A, Patel NM (2019) Causative agents of urinary tract infections and their antimicrobial susceptibility patterns at a referral center in Western India: An audit to help clinicians prevent antibiotic misuse. J Fam Med Prim Care 8(1):154-159

2. Gupta S, Kapur S, Padmavathi D (2014) Comparative prevalence of antimicrobial resistance in community-acquired urinary tract infection cases from representative states of Northern and Southern India. J Clin Diagn Res 8:9-12

3. Manoharan AL, Thamburaj S, Muniyandi K, Jagadeesan G, Sathyanaraynan S, Nataraj G, Thangaraj P (2019) Antioxidant and antimicrobial investigations of Elaeocarpus tectorius (Lour.) Poir. fruits against urinary tract infection pathogens. Biocatal Agric Biotechnol 20:101260

4. Grigoryan L, Trautner BW, Gupta K (2014) Diagnosis and management of urinary tract infections in the outpatient setting: a review. JAMA 312(16):1677-1684

5. Shaheen G, Akram M, Jabeen F, Ali Shah SM, Munir N, Daniyal M, Riaz M, Tahir IM, Ghauri AO, Sultana S, Zainab R, Khan M (2019) Therapeutic potential of medicinal plants for the management of urinary tract infection: a systematic review. Clin Exp Pharmacol Physiol 46(7):613-624

6. Sureshkumar J, Ayyanar M, Silambarasan R (2021) Ethnomedicinal uses, phyto-constituents and pharmacological importance of pteridophytes used by Malayalis in Kolli hills, India: a quantitative survey. J Herb Med 25:1-9

7. Altundag E, Ozturkb M (2011) Ethnomedicinal studies on the plant resources of East Anatolia, Turkey. Procedia Soc Behav Sci 19:756-777

8. Sureshkumar J, Silambarasan R, Bharati KA, Krupa J, Amalraj S, Ayyanar M (2018) A review on ethnomedicinally important pteridophytes of India. J Ethnopharmacol 219:269-287

9. Alebous H, Hudaib M, Hudeb A, Sober S, Gray R, Johnson MD (2016) Chemical composition of essential oil from Equisetum ramosissimum. Eur J Med Plants 13(2):1-5

10. Saleh NAM, Abdalla MF (1980) The flavonoids of Equisetum ramosissimum. Phytochemistry 19:987

11. Chiu P, Patterson GW, Salt TA (1988) Sterol composition of pteridophytes. Phytochemistry 27(3):819-822

12. Manickam VS, Irudayaraj V (1992) Pteridophyte flora of the Western Ghats (South India). B.I. Publications Pvt. Ltd, New Delhi

13. Harborne JB (1998) Phytochemical methods: a guide to moderntechniques of plant analysis. Chapman and Hall, London

14. Adams RP (2007) Identification of essential oil components by gaschromatography/quadrupole mass spectroscopy, 4th edn. Allured Publishing Corporation, Carol Stream

15. Thangaraj T (2016) Pharmacological assays of plant-based natural products. Prog Drug Res 71:49-55
16. Amalraj S, Krupa J, Sriramavaratharajan V, Mariyammal V, Murugan R, Ayyanar M (2021) Chemical characterization, antioxidant, antibacterial and enzyme inhibitory properties of Canthium coromandelicum, a valuable source for bioactive compounds. J Pharm Biomed Anal 192:1-12

17. Bouaziz B, Abdalla S, Baghiani A, Charef N (2015) Phytochemical analysis, hypotensive effect and antioxidant properties of Myrtus communis L. growing in Algeria. Asian Pac J Trop Biomed 5:19-28

18. Amalraj S, Mariyammal V, Murugan R, Gurav SS, Krupa J, Ayyanar M (2021) Comparative evaluation on chemical composition, in vitro antioxidant, antidiabetic and antibacterial activities of various solvent extracts of Dregea volubilis leaves. S Afr J Bot 138:115-123

19. Carta G, Murru E, Banni S, Manca C (2017) Palmitic acid: physiological role, metabolism and nutritional implications. Front Physiol 8:902

20. Fatima S, Hu X, Gong R, Huang C, Chen M, Wong H, Bian Z, Kwan H (2019) Palmitic acid is an intracellular signaling molecule involved in disease development. Cell Mol Life Sci 76:2547-2557

21. Taha A (2020) Linoleic acid-good or bad for the brain? NPJ Sci Food 4:1. https://doi.org/10.1038/s41538-019-0061-9

22. Sanders TAB. Functional dietary lipids, food formulation, consumer issues and innovation for health. Woodhead Publishing series in food science, technology and nutrition; 2016. p. 1-20. https://doi.org/10. 1016/C2013-0-16501-4.

23. Fox PF (2003) The major constituents of milk. In: Smit G, editors. Dairy processing-improving quality. Woodhead Publishing series in food science, technology and nutrition. p. 5-41. https://doi.org/10.1533/ 9781855737075.1 .5

24. Chen Y, Wang E, Wei Z, Zheng Y, Yan R, Ma X (2019) Phytochemical analysis, cellular antioxidant and a-glucosidase inhibitory activities of various herb plant organs. Ind Crops Prod 141:1-11

25. Radojevic ID, Stankovic MS, Stefanovic OD, Topuzovic MD, Comic LR, Ostojic AM (2012) Great horsetail (Equisetum telmateia Ehrh.): active substances content and biological effects. EXCLI J 11:59-67

26. Stajner D, Popovic BM, Canadanovic-Brunet J, Anackov G (2009) Exploring Equisetum arvense L., Equisetum ramosissimum L. and Equisetum telmateia $\mathrm{L}$. as sources of natural antioxidants. Phytother Res 23:546-550

27. Tsao R, Deng Z (2004) Separation procedures for naturally occurring antioxidant phytochemicals. J Chromatogr B Analyt Technol Biomed Life Sci 812(1-2):85-99

28. Sindhi V, Gupta V, Sharma K, Bhatnagar S, Kumari R, Dhaka N (2013) Potential applications of antioxidants: a review. J Pharm Res 7:828-835

29. Ahmed AF, Shi M, Liu C, Kang W (2019) Comparative analysis of antioxidant activities of essential oils and extracts of fennel (Foeniculum vulgare Mill.) seeds from Egypt and China. Food Sci Hum Well 8:67-72

30. Panat NA, Maurya DK, Ghaskadbi SS, Sandur SK (2016) Troxerutin, a plant flavonoid, protects cells against oxidative stress-induced cell death through radical scavenging mechanism. Food Chem 194:32-45

31. Paulsamy S, Moorthy D, Nandakumar K, Saradha M (2013) Evaluation of in vitro antioxidant potential of methanolic extracts of the ferns, Actiniopteris radiata (SW) Link. and Equisetum ramosissimum Desf. Int J Res Dev Pharm Life Sci 2(3):451-455

32. Li P, Chiu Y, Shih C, Wen Z, Ibeto LK, Huang S, Chiu CC, Ma D, Leung C, Chang Y, David Wang H (2016) Biofunctional activities of Equisetum ramosissimum extracts; protective effects against oxidation, melanoma and melanogenesis. Oxid Med Cell Longev 3:1-9

33. Alexandru V, Gaspar A, Savin S, Toma A, Tatia R, Gille E (2015) Phenolic content, antioxidant activity and effect on collagen synthesis of a traditional wound healing polyherbal formula. Stud Univ Vasile Goldis Arad Ser Stiint Vietii 25(1):41-46

34. Nagai T, Myoda T, Nagashima T (2005) Antioxidative activities of water extract and ethanol extract from field horsetail (tsukushi) Equisetum arvense L. Food Chem 91:389-394

35. Canadanovic-Brunet JM, Cetkovic GS, Djilas SM, Tumbas VT, Savatovic SS, Mandic Al, Markov SL, Cvetkovic DD (2009) Radical scavenging and antimicrobial activity of horsetail (Equisetum arvense L.) extracts. Int J Food Sci Technol 44:269-278 
36. Sarkar B, Raihan SMA, Sultana N, Rahman R, Islam ME, Ahmed S, Akter $S$ (2012) Cytotoxic, antibacterial and free radical scavenging activity studies of the solvent extracts of aerial stems of Equisetum debile Roxb. Int J Chem Sci 10(1):19-26

37. Alves CFS, Bonez PC, Souza ME, Cruz RC, Boligon AA, Piana M, Brum TF, Rossi GG, Jesus RS, Grando TH, Monteiro SG, Campos MMA, Giongo JL, Santos RCV (2016) Antimicrobial, antitrypanosoma and antibiofilm activity of Equisetum hyemale. Microb Pathog 101:119-125

\section{Publisher's Note}

Springer Nature remains neutral with regard to jurisdictional claims in published maps and institutional affiliations.

\section{Submit your manuscript to a SpringerOpen ${ }^{\odot}$ journal and benefit from:}

- Convenient online submission

- Rigorous peer review

- Open access: articles freely available online

- High visibility within the field

- Retaining the copyright to your article

Submit your next manuscript at $\boldsymbol{\nabla}$ springeropen.com 